\title{
Comments on the article "Clinical and radiological outcomes of fixed- versus mobile-bearing total knee replacement: a meta-analysis"
}

\author{
W. C. H. Jacobs
}

Received: 28 October 2009/Accepted: 19 February 2010/Published online: 8 April 2010

(C) The Author(s) 2010. This article is published with open access at Springerlink.com

\section{Dear Editors,}

With interest I have been reading the article "Clinical and radiological outcomes of fixed- versus mobile-bearing total knee replacement: a meta-analysis", by Smith et al. [10] recently published in this journal.

I would like to congratulate the authors with performing a systematic review with meta-analysis. The basic requirements are met for a systematic approach and the authors have an excellent data presentation. Having a strong heart for the quality of systematic reviews, I feel obliged to make a few remarks concerning some issues with the methodology and results of the presented material which made me sometimes wonder and sometimes merely confused.

The authors choose to include retrospective material. In retrospective studies, the data are not gathered with a specific question in mind and selection bias might be present because it is difficult to reconstruct the referral strategies to the experimental and control groups. I would be interested in a best evidence approach appreciating the study types.

The authors neglect the status of the posterior cruciate ligament in the knee arthroplasties in the included studies. As shown in the Cochrane review by Jacobs et al. [5], the clinical outcome depends on the existence of a post-and-

\section{W. C. H. Jacobs}

Department of Research, Development and Education, Orthopedic Research Unit, Sint Maartenskliniek, Nijmegen, The Netherlands

\section{Present Address:}

W. C. H. Jacobs $(\square)$

Department of Neurosurgery, Leiden University Medical Center, P.O. Box 9600, 2300 RC Leiden, The Netherlands

e-mail: w.c.h.jacobs@lumc.nl cam mechanism in cruciate sacrificing implants. Neglecting this effect introduces heterogeneity in the included studies which should be addressed in a subgroup analysis.

I can fully support the inclusion of grey literature in systematic reviews, if analysed accordingly. However, the authors used a very limited search strategy to identify relevant studies in the white literature to begin with. To my knowledge there are a few additional trials that have been missed. The addition of grey literature to an inferior primary search does not add to the quality of the review.

I wonder if the separately analysed AKSS and KSS might refer to the same (American) Knee Society Score. At least two studies (Price et al. [9] (AKSS) and Kim et al. [7] (KSS)) refer to the well known score of Insall et al. [4] These outcome scores were separately analysed, resulting in a significant difference in the functional KSS. If referring to the same score, the KSS and AKSS should be analysed together, possibly removing the effect.

One more problem with the found difference is the standard deviation (SD) used. Typical SD for KSS clinical and functional scores is about $10-15$, as we can see in fig 3 . However, for the study of Munoz et al. [8], the SD for functional KSS is only 2.3. Being this low, this study loads almost entirely on the pooled effect. Looking at the original paper of Munoz et al. [8], they report a range of functional KSS of 55-100 for the fixed type and 54-100 in the mobile group. The authors do not report their method of inferring SDs from ranges, but usually we can divide the range by 4 , yielding an SD for the study of Munoz et al. [8] of approximately 11 . Similarly, I also question an SD of 122.7 in the study of Biau et al.

I was finally rather confused by the differences between Tables 1 and 6 regarding the judgement of study type (RCT, observational or retrospective) for the studies of 
Aglietti et al. [1], Bhan et al. [2], Henricson et al. [3], Kim et al. [7], and Kim et al. [6].

I hope the authors can shed some light on these issues.

Conflict of interest I am the primary author of the Cochrane review: Jacobs W, Anderson P, Limbeek J, Wymenga A. (2004) "Mobile-bearing vs fixed-bearing prostheses for total knee arthroplasty for post-operative functional status in patients with osteoarthritis and rheumatoid arthritis" Cochrane Database Syst Rev 2: 10.1002/14651858.CD003130.pub2 [doi]. This review is currently being updated.

Open Access This article is distributed under the terms of the Creative Commons Attribution Noncommercial License which permits any noncommercial use, distribution, and reproduction in any medium, provided the original author(s) and source are credited.

\section{References}

1. Aglietti P, Baldini A, Buzzi R, Lup D, De LL (2005) Comparison of mobile-bearing and fixed-bearing total knee arthroplasty: a prospective randomized study. J Arthroplasty 20:145-153

2. Bhan S, Malhotra R (2003) Results of rotating-platform, lowcontact-stress knee prosthesis. J Arthroplasty 18:1016-1022

3. Henricson A, Dalen T, Nilsson KG (2006) Mobile bearings do not improve fixation in cemented total knee arthroplasty. Clin Orthop Relat Res 448:114-121
4. Insall JN, Dorr LD, Scott RD, Scott WN (1989) Rationale of the knee society clinical rating system. Clin Orthop Relat Res 248:13-14

5. Jacobs WC, Clement DJ, Wymenga AB (2005). Retention versus sacrifice of the posterior cruciate ligament in total knee replacement for treatment of osteoarthritis and rheumatoid arthritis. Cochrane Database Syst Rev 4. doi:10.1002/14651858. CD004803.pub2

6. Kim YH, Kim DY, Kim JS (2007) Simultaneous mobile- and fixed-bearing total knee replacement in the same patients. A prospective comparison of mid-term outcomes using a similar design of prosthesis. J Bone Joint Surg Br 89:904-910

7. Kim YH, Yoon SH, Kim JS (2007) The long-term results of simultaneous fixed-bearing and mobile-bearing total knee replacements performed in the same patient. J Bone Joint Surg Br 89:1317-1323

8. Munoz AS, Herrero FA, Lozano RL, Linares FA (2008) Comparison of mobile- and fixed-bearing cemented total knee arthroplasty. Acta Orthop Belg 74:801-808

9. Price AJ, Rees JL, Beard D, Juszczak E, Carter S, White S, de SR, Dodd CA, Gibbons M, McLardy-Smith P, Goodfellow JW, Murray DW (2003) A mobile-bearing total knee prosthesis compared with a fixed-bearing prosthesis. A multicentre singleblind randomised controlled trial. J Bone Joint Surg Br 85:62-67

10. Smith TO, Ejtehadi F, Nichols R, Davies L, Donell ST, Hing CB (2009). Clinical and radiological outcomes of fixed- versus mobile-bearing total knee replacement: a meta-analysis. Knee Surg Sports Traumatol Arthrosc 18:325-340 (Sep 25:[Epub ahead of print]. doi:10.1007/s00167-009-0909-7) 